\title{
Performance Appraisal Method Used in Top 10 IT Companies-360 Degree Feedback \& Balanced Score Card: A Review
}

\author{
K. Chandhana and Dr. David T Easow
}

\begin{abstract}
India is the world's largest sourcing destination for the IT industry, accounting for approximately $52 \%$ of US \$ 124-130 billion market. India employs about 10 million Indians and continues to contribute significantly to the economic transformation of the country. Hence IT sector is considered to be one of the highest contributing sectors towards GDP. Being such an opportunity driven sector, attrition rate in this sector is also quiet high. In addition to that the attrition rate with respect to dissatisfaction in the performance appraisal methods used is $18.7 \%$. Thus performance appraisal methods used in the organization plays a vital role in determining the employee's performance, as well as the satisfaction level of the employee towards the performance appraisal method used. It is considered to be one of the important factors motivating the employees to perform on par or above the standard set. This paper is a study of performance appraisal methods used by the top 10 IT companies (based on revenue-2014) which includes - TCS, Infosys, Wipro, Tech Mahindra, HCL Technologies, Mphasis, Oracle Financial Services, Mindtree, Polaris Technology and Rolta India sequentially. Coincidentally these companies use either 360 degree feedback or Balanced Score Card. Thus this paper is a review of 360 degree feedback and balanced score card, analyzing its advantages, disadvantages and reasons for using the method.
\end{abstract}

Keywords--- IT Sector, Performance Appraisal, 360 Degree Feedback, Balanced Score Card

\section{INTRODUCTION}

$\mathrm{I}$ NFORMATION technology (IT) industry in India has played a key role in putting India on the global map. IT industry in India has been one of the most significant growth contributors for the Indian economy. This has projected India's image as a global player in providing world class technology solutions and business services. The transformation from an agriculture based country to a knowledge based country has high credentials to IT sector.

IT-ITeS sector in India, with the main focus on increasing technology adoption, and developing new delivery platforms, has aggregated revenues of USD 124-130 billion. The top 10 IT companies (based on revenue-2014 report) which includes

K. Chandhana, Research Scholar, Hindustan University

Dr. David T Easow, Deputy Director (SoM \& International Affairs), Hindustan University

DOI: 10.9756/BIJIEMS.8082
- TCS, Infosys, Wipro, Tech Mahindra, HCL Technologies, Mphasis, Oracle Financial Services, Mindtree, Polaris Technology and Rolta India are the trend setters of the market in many aspects.

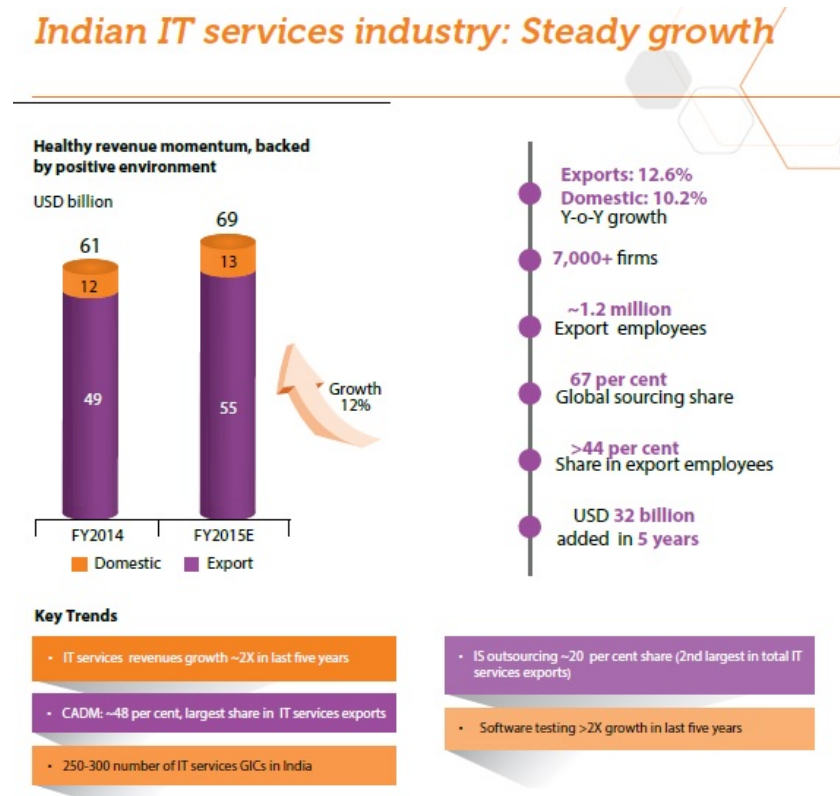

India, the fourth largest base for young businesses in the world and home to 3,000 tech start-ups, is set to increase its base to 11,500 tech start-ups by 2020 , as per a report by Nasscom and Zinnov Management Consulting Private Ltd.

Emerging technologies present an entire new gamut of opportunities for IT firms in India.

The computer software and hardware sector in India attracted cumulative foreign direct investment (FDI) inflows worth US\$ 13,788.56 million between April 2000 and December 2014, according to data released by the Department of Industrial Policy and Promotion (DIPP).

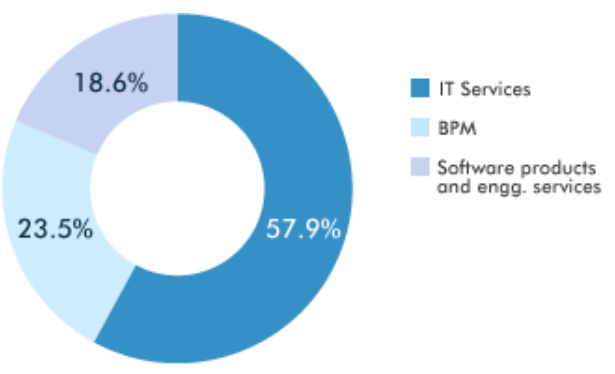


Employment opportunities are huge in IT sector which in turn reflects upon the employee retention and employee's performance standard. The performance of an employee is measured and evaluated with the use of performance appraisal methods of the company. But the pitfall is the day to day increasing grievance towards the appraisal methods used in the organisations. Performance appraisal plays a vital role in determining the employee's performance, as well as the satisfaction level of the employee towards the performance appraisal method used.

Performance Appraisal is the systematic evaluation of the performance of employees and to understand the abilities of a person for further growth and development. Performance appraisal is generally done in systematic ways which are as follows:

- The supervisors measure the pay of employees and compare it with targets and plans.

- The supervisor analyses the factors behind work performances of employees.

- The employers are in position to guide the employees for a better performance.

"It is a systematic evaluation of an individual with respect to performance on the job and individual's potential for development."

Employees who work only for money quit after a salary hike to negotiate further with any other organization. Individuals who do not get satisfactory appraisal in any case get demotivated and look for a change. Any employee who does not agree to his/her appraisal or feel has not got what he/she deserves needs to be addressed at the earliest.

4 Goals of Performance Appraisals

\begin{tabular}{|l|l|}
\hline General Goals & Specific Goals \\
\hline Developmental Use & Individual needs \\
& Performance feedback \\
& Transfers and Placements \\
& Strengths and Development needs \\
\hline Administrative Decisions / & Salary \\
Uses & Promotion \\
& Retention / Termination \\
& Recognition \\
& Lay offs \\
& Poor Performers identification \\
\hline Organizational Maintenance & HR Planning \\
& Training Needs \\
& Organizational Goal achievements \\
& Goal Identification \\
& HR Systems Evaluation \\
& Reinforcement of organizational \\
& needs \\
\hline Documentation & Validation Research \\
& For HR Decisions \\
& Legal Requirements \\
\hline
\end{tabular}

There are several performance appraisal methods used by IT sector as a whole. But this paper focuses only on the methods used by the top ten IT companies, as they are the market leaders of this sector. Amidst the high competition in the market, the top ten IT companies uses either of two methods - 360 degree feedback or balanced score card. Hence this paper throws light on the two methods used by the top most IT companies.

\section{360 DEGREE FEEDBACK}

The 360 evaluation feedback method was first used in the 1940s. It is a system or process in which employees receive confidential, anonymous feedback from the people who work around them. Analogous to the multiple points on a compass, the 360 method provides each employee the opportunity to receive performance feedback from his or her supervisor, peers, staff members, co-workers and customers.

Usually, this tool is used for employees at middle and senior level. The complexity of their roles enables the organization to generate sufficient data from all stakeholders for a meaningful assessment.

Most organizations that focus on employee development use the 360-degree tool to assess performance and potential of staff and enable the employees to map their career path based on the feedback. Organizations take 360-degree feedback about an employee before taking a major decision about the professional's career.

\section{Advantages of 360 Degree Feedback}

The 360 feedback system automatically tabulates the results and presents them in a format that helps the feedback recipient create a development plan. Individual responses are always combined with responses from other people in the same rater category (e.g. peer, direct report) in order to preserve anonymity and to give the employee a clear picture of his/her greatest overall strengths and weaknesses.

When done properly, 360 degree feedback is highly effective as a development tool. The feedback process gives people an opportunity to provide anonymous feedback to a coworker that they might otherwise be uncomfortable giving. Feedback recipients gain insight into how others perceive them and have an opportunity to adjust behaviors and develop skills that will enable them to excel at their jobs.

360 degree feedback is the most comprehensive appraisal where the feedback about the employees' performance comes from all the sources that come in contact with the employee on his job.360-degree Feedback, or multi-rater feedback, is used by $90 \%$ of Fortune 500 companies (Carruthers, 2003).

360 degree appraisal has four integral components:

- Self appraisal

- Superior's appraisal

- Subordinate’s appraisal

- Peer appraisal.

Self appraisal is the best way to analyze one's strength and weakness, performance standards, areas of improvement; whereas the superior's appraisal form is the traditional part of the 360 degree feedback method where the employee's performance is evaluated by the superior. Subordinates appraisal gives a chance to judge the employee on the parameters like communication and motivating abilities, superior's ability to delegate the work, leadership qualities etc. Also known as internal customers, the correct feedback given 
by peers can help to find employees' abilities to work in a team, co-operation and sensitivity towards others.

The primary reason to use this full circle of confidential reviews is to provide the worker with information about his/her performance from multiple perspectives. From this feedback, the worker is able to set goals for self-development which will advance their career and benefit the organization.

Under ideal circumstances, 360-degree feedback is used as an assessment for personal development rather than evaluation (Tarnow, W., 1998). Criticisms are seen as opportunities for improvement (Randel, A., 2004).

Feedback tool includes area for comments (Hoffmanner, A., 2004).

This method has got high employee involvement and also has the strongest impact on behavior and performance. It provides a "360-degree review" of the employees' performance and is considered to be one of the most credible performance appraisal methods.

To comprehend the advantages and strengths of using 360 degree feedback:

- Offer a more comprehensive view towards the performance of employees.

- Improve credibility of performance appraisal.

- Colleague's feedback will help strengthen selfdevelopment.

- Increases responsibilities of employees to their customers.

- The mix of ideas can give a more accurate assessment.

- Opinions gathered from lots of staff are sure to be more persuasive.

- Not only manager should make assessments on its staff performance but other colleagues should do, too.

- People who undervalue themselves are often motivated by feedback from others.

- If more staff takes part in the process of performance appraisal, the organizational culture of the company will become more honest.

- Improved Feedback From More Sources.

- Team development.

- Personal and Organizational development

- Responsibility for career development

- Reduced discrimination risk.

- Reduces manager bias. Since a lot of people give feedback, any extreme rating between a manager and others can be looked into and the reasons can be found out.

\section{Disadvantages of 360 Degree Feedback}

It is difficult to properly structure a 360 feedback process that creates an atmosphere of trust when you use 360 evaluations to measure performance.360 degree feedback focuses on behaviors and competencies more than on basic skills, job requirements, and performance objectives.

Feedback tied to merit pay or promotions. Comments traced to individuals causing resentment between workers. Excessive number of surveys are required of each worker with few tangible results provided to individuals (Clark, S., Whittall, A., 2003)

360 degree feedbacks that get driven by HR without much attention from the boss are not effective. Whatever the boss gives importance to gets the attention of his/her reports. The boss has to be a believer that this stuff helps the team.

People offer comment that are personal in nature rather than constructive.360 degree feedback data is only helpful to the extent that it gets acted upon and used.

One of the major drawbacks is that the evaluating process will be too much focused on weakness of the employee. Forgetting the strengths and only focusing on weaknesses demotivates employees.

The entire process depends solely on the Rater. If the Rater is inexperienced and ineffective the process becomes invalid.

Paperwork/Computer data entry overload also acts as a disadvantage.

Businesses willing to implement this comprehensive method of assessment should be willing to spend the time and effort necessary to train each anonymous evaluator in the process as well as correct and incorrect ways to interpret questions. Failure to properly train feedback providers will most likely result in inaccurate results or a total failure of the process to produce relevant information. The system will fail if it is an add-on rather than a supporter of your organization's fundamental direction and requirements. It must function as a measure of your accomplishment of your organization's big and long term picture.

\section{BALANCED SCORE CARD}

Balanced Score Card is a strategic planning and management system that is used extensively in business and industry, government, and nonprofit organizations worldwide to align business activities to the vision and strategy of the organization, improve internal and external communications, and monitor organization performance against strategic goals. It was originated by Drs. Robert Kaplan (Harvard Business School) and David Norton as a performance measurement framework that added strategic non-financial performance measures to traditional financial metrics to give managers and executives a more 'balanced' view of organizational performance. The balanced scorecard has evolved from its early use as a simple performance measurement framework to a full strategic planning management system.

Balanced scorecard method addresses four business perspectives, which are as follows:

- Financial Perspective

- Customer Perspective

- Learning and Growth Perspective

- Business Process 


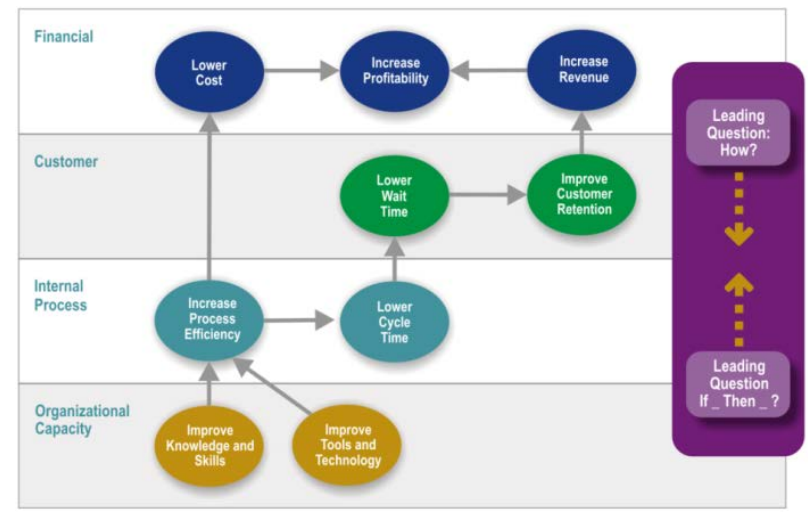

There are four processes in which balanced score card relies on. They are translating the vision, communicating and linking, business planning and feedback and learning.

The first new process: translating the vision-helps managers build a consensus around the organization's vision and strategy. Despite the best intentions of those at the top, lofty statements about becoming "best in class," "the number one supplier," or an "empowered organization” don't translate easily into operational terms that provide useful guides to action at the local level. For people to act on the words in vision and strategy statements, those statements must be expressed as an integrated set of objectives and measures, agreed upon by all senior executives, that describe the longterm drivers of success.

The second process: communicating and linking-lets managers communicate their strategy up and down the organization and link it to departmental and individual objectives. Traditionally, departments are evaluated by their financial performance, and individual incentives are tied to short-term financial goals. The scorecard gives managers a way of ensuring that all levels of the organization understand the long-term strategy and that both departmental and individual objectives are aligned with it.

The third process: business planning_enables companies to integrate their business and financial plans. Almost all organizations today are implementing a variety of change programs, each with its own champions, gurus, and consultants, and each competing for senior executives' time, energy, and resources. Managers find it difficult to integrate those diverse initiatives to achieve their strategic goals-a situation that leads to frequent disappointments with the programs' results. But when managers use the ambitious goals set for balanced scorecard measures as the basis for allocating resources and setting priorities, they can undertake and coordinate only those initiatives that move them toward their long-term strategic objectives.

The fourth process: feedback and learning-gives companies the capacity for what we call strategic learning. Existing feedback and review processes focus on whether the company, its departments, or its individual employees have met their budgeted financial goals. With the balanced scorecard at the center of its management systems, a company can monitor short-term results from the three additional perspectives-customers, internal business processes, and learning and growth-and evaluate strategy in the light of recent performance. The scorecard thus enables companies to modify strategies to reflect real-time learning.

\section{Advantages of Balanced Score Card}

The balanced scorecard transforms an organization's strategic plan from an attractive but passive document into the "marching orders" for the organization on a daily basis. It provides a framework that not only provides performance measurements, but helps planners identify what should be done and measured. It enables executives to truly execute their strategies.

Without a balanced scorecard, most organizations are unable to achieve a similar consistency of vision and action as they attempt to change direction and introduce new strategies and processes. The balanced scorecard provides a framework for managing the implementation of strategy while also allowing the strategy itself to evolve in response to changes in the company's competitive.

Managers using the balanced scorecard do not have to rely on short-term financial measures as the sole indicators of the company's performance. The scorecard lets them introduce four new management processes that, separately and in combination, contribute to linking long-term strategic objectives with short-term actions.

\section{Companies are using the scorecard to}

- $\quad$ Clarify and update strategy;

- Communicate strategy throughout the company;

- $\quad$ Align unit and individual goals with the strategy;

- Link strategic objectives to long-term targets and annual budgets;

- Identify and align strategic initiatives; and

- $\quad$ Conduct periodic performance reviews to learn about and improve strategy.

\section{Disadvantages of Balanced Score Card}

It takes time to adapt to balanced scorecard strategic system. So this will require a lot of motivation from the management to be able to successfully complete the process.

Balanced scorecard gives you an extensive overview of the company. It will give you facts about your company's execution and performance. But it will not give you recommendations on how to amend strategies and policies to overcome discrepancies. Therefore, for attainment of a complete analysis of a company's performance, a more magnanimous strategy will be required.

While the balanced scorecard gives you an overall view of the four areas for concern in business growth and development, these four areas do not paint the whole picture. The financial information included on the scorecard is limited. Instead, to be successfully implemented, the balanced scorecard must be part of a bigger strategy for company growth that includes meticulous accounting methods.

Many companies use metrics that are not applicable to their own situation. It is vitally important when using balanced scorecards to make the information being tracked applicable to their needs. Otherwise, the metrics will be meaningless. 
Balanced Score Card system will require a high initial cost and time spent. This will make the balance sheet depict that the company is not making profit and that implementing the balanced scorecard system is a waste of money.

\section{CONCLUSION}

Human resources are the vital source of every organization. Every employee in an organization increases the productivity and goodwill of every company. An employee, being an individual is treated as assets in the organization. So the organization should mainly emphasis performance appraisal techniques and its development program. Both the appraiser and appraise should realize the principle and use the tool of appraisal system in a constructive way for the prosperity of the organization.

Both 360 degree feedback and balanced score card has its own loopholes, though these methods are being used by top IT companies. The satisfaction level of employees towards these appraisal methods are very low (source: discussions in the HR forums like citeHR.com) and there is a need of a new appraisal method which prevents these errors and have the advantages of these methods.

\section{REFERENCE}

[1] Aguinis.H and Printice Hall, “Performance management”, 2007.

[2] Ashwathappa.K, "Human Resource and personnel management", 1997.

[3] Boswell W. R. and Boudreau J. W.,"Employee satisfaction with performance appraisals and appraisers: The role of perceived appraisal use. Human Resource Development”, vol. 11, 2000.

[4] Boswell W. R. and Boudreau J.W., "Separating the developmental and evaluative performance appraisal uses. Journal of Business \& Psychology", Vol. 16, 2002.

[5] Cokins, G, John Wiley and Sons,“Performance management: Finding the missing pieces and closing the intelligence gap”, 2004.

[6] Decenzo, D. A, Robbins and Stephen P, "Human resource management"7th edition, 2002.

[7] Fletcher.C, "Appraisal and Feedback: Making Performance Review Work”, CIPD, 2004.

[8] Greer,R. Strategic Human Resource Management: A general managerial approach, 2001.

[9] Weihrich, H. Essentials of Management: An International Perspective, 2005. 